Article

\title{
Coronary Flow Velocity Reserve Using Dobutamine Test for Noninvasive Functional Assessment of Myocardial Bridging
}

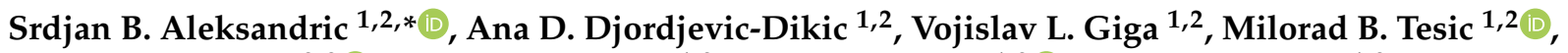
Ivan A. Soldatovic 2,3 ${ }^{\mathbb{D}}$, Marko D. Banovic ${ }^{1,2}$, Milan R. Dobric ${ }^{1,2} \mathbb{D}_{\text {, Vladan Vukcevic }}{ }^{1,2}$, Miloje V. Tomasevic ${ }^{1,4}$, Dejan N. Orlic ${ }^{1,2}$, Nikola Boskovic ${ }^{1}$, Ivana Jovanovic ${ }^{1}$, Milan A. Nedeljkovic ${ }^{1,2}$, Goran Stankovic 1,2 (D), Miodrag C. Ostojic ${ }^{2,5}$ and Branko D. Beleslin ${ }^{1,2}$

1 Cardiology Clinic, University Clinical Center of Serbia, 11000 Belgrade, Serbia; skali.ana7@gmail.com (A.D.D.-D.); voja2011@yahoo.com (V.L.G.); misa.tesic@gmail.com (M.B.T.); markobanovic71@gmail.com (M.D.B.); iatros007@gmail.com (M.R.D.); vladan.vukcevic@gmail.com (V.V.); milojetomasevic@gmail.com (M.V.T.); orlicmail@yahoo.com (D.N.O.); belkan87@gmail.com (N.B.); ivana170679@gmail.com (I.J.); milanned@hotmail.com (M.A.N.); gorastan@gmail.com (G.S.); branko.beleslin@gmail.com (B.D.B.)

2 Faculty of Medicine, University of Belgrade, 11000 Belgrade, Serbia; soldatovic.ivan@gmail.com (I.A.S.); mostojic2011@gmail.com (M.C.O.)

3 Institute of Medical Statistics and Informatics, Faculty of Medicine, University of Belgrade, 11000 Belgrade, Serbia

4 Department of Internal Medicine, Faculty of Medical Sciences, University of Kragujevac, 34000 Kragujevac, Serbia

check for updates

Citation: Aleksandric, S.B. Djordjevic-Dikic, A.D.; Giga, V.L.; Tesic, M.B.; Soldatovic, I.A.; Banovic, M.D.; Dobric, M.R.; Vukcevic, V.; Tomasevic, M.V.; Orlic, D.N.; et al. Coronary Flow Velocity Reserve Using Dobutamine Test for Noninvasive Functional Assessment of Myocardial Bridging. J. Clin. Med. 2022, 11, 204. https://doi.org/ $10.3390 /$ jcm11010204

Academic Editors: Eugenio Picano and Ernesto Di Cesare

Received: 27 November 2021 Accepted: 23 December 2021 Published: 30 December 2021

Publisher's Note: MDPI stays neutral with regard to jurisdictional claims in published maps and institutional affiliations.

Copyright: (C) 2021 by the authors. Licensee MDPI, Basel, Switzerland. This article is an open access article distributed under the terms and conditions of the Creative Commons Attribution (CC BY) license (https:// creativecommons.org/licenses/by/ $4.0 /)$.
5 Institute for Cardiovascular Diseases Dedinje, 11000 Belgrade, Serbia

* Correspondence: srdjanaleksandric@gmail.com

Abstract: Background: It has been shown that coronary flow velocity reserve (CFVR) measurement by transthoracic Doppler echocardiography (TTDE) during dobutamine (DOB) provocation provides a more accurate functional evaluation of myocardial bridging (MB) compared to adenosine. However; the cut-off value of CFVR during DOB for identification of MB associated with myocardial ischemia has not been fully clarified. Purpose: This prospective study aimed to determine the cut-off value of TTDE-CFVR during DOB in patients with isolated-MB, as compared with stress-induced wall motion abnormalities (VMA) during exercise stress-echocardiography (SE) as reference. Methods: Eighty-one symptomatic patients (55 males [68\%], mean age $56 \pm 10$ years; range: 27-74 years) with the existence of isolated-MB on the left anterior descending artery (LAD) and systolic MB-compression $\geq 50 \%$ diameter stenosis (DS) were eligible to participate in the study. Each patient underwent treadmill exercise-SE, invasive coronary angiography, and TTDE-CFVR measurements in the distal segment of LAD during DOB infusion (DOB: $10-40 \mu \mathrm{g} / \mathrm{kg} / \mathrm{min}$ ). Using quantitative coronary angiography, both minimal luminal diameter (MLD) and percent DS at MB-site at end-systole and end-diastole were determined. Results: Stress-induced myocardial ischemia with the occurrence of WMA was found in 23 patients (28\%). CFVR during peak DOB was significantly lower in the SE-positive group compared with the SE-negative group (1.94 \pm 0.16 vs. $2.78 \pm 0.53 ; p<0.001)$. ROC analyses identified the optimal CFVR cut-off value $\leq 2.1$ obtained during high-dose dobutamine ( $>20 \mu \mathrm{g} / \mathrm{kg} / \mathrm{min}$ ) for the identification of MB associated with stress-induced WMA, with a sensitivity, specificity, positive and negative predictive value of $96 \%, 95 \%, 88 \%$, and $98 \%$, respectively (AUC $0.986 ; 95 \%$ CI: $0.967-1.000 ; p<0.001)$. Multivariate logistic regression analysis revealed that MLD and percent DS, both at end-diastole, were the only independent predictors of ischemic CFVR values $\leq 2.1$ (OR: 0.023; 95\% CI: 0.001-0.534; $p=0.019$; OR: 1.147; 95\% CI: 1.042-1.263; $p=0.005$; respectively). Conclusions: Noninvasive CFVR during dobutamine provocation appears to be an additional and important noninvasive tool to determine the functional severity of isolated-MB. A transthoracic CFVR cut-off $\leq 2.1$ measured at a high-dobutamine dose may be adequate for detecting myocardial ischemia in patients with isolated-MB.

Keywords: myocardial bridging; myocardial ischemia; stress-echocardiography; coronary flow velocity reserve; transthoracic Doppler echocardiography; dobutamine 


\section{Introduction}

Coronary flow velocity reserve (CFVR) measured by transthoracic Doppler echocardiography (TTDE) is a clinically useful and feasible noninvasive diagnostic index for the assessment of fixed coronary stenosis severity [1-8]. Although adenosine-induced maximal hyperemia is considered a gold standard for TTDE-CFVR measurements in the functional assessment of fixed coronary stenosis, the functional assessment of myocardial bridging (MB) is less reliable [9-14]. Despite being considered a benign coronary lesion, MB may cause life-threatening events such as ventricular arrhythmias, acute coronary syndrome, or even sudden cardiac death [15-18]. As a result of these events, concerns have been raised regarding its clinical significance and the need for appropriate diagnostic test/s which could be helpful in the identification of MB associated with myocardial ischemia [14]. Therefore, previous studies indicate that the functional assessment of MB should include dobutamine provocation with possibly exaggerated extravascular systolic coronary artery compression [9-14]. Additionally, the feasibility of assessing CFVR by TTDE during dobutamine provocation is high and the steady-state hyperemia induced with a high-doses of dobutamine ( $>20 \mu \mathrm{g} / \mathrm{kg} / \mathrm{min})$ is similar to adenosine-induced one [13,14,19-26]. Recently, it has been demonstrated that TTDE-CFVR measured at high-dose dobutamine provides a more accurate functional evaluation of MB compared to adenosine [13]. Still, CFVR obtained by TTDE has not been thoroughly evaluated to determine whether it is useful for functional assessment of MB severity. Therefore, the purpose of the study was to evaluate the adequate cut-off value of TTDE-CFVR during dobutamine provocation, as compared with exercise-induced myocardial ischemia as reference.

\section{Methods}

\subsection{Study Population}

Eighty-one symptomatic patients (55 males [68\%], mean age $56 \pm 10$ years, range: 27-74 years) undergoing coronary angiography due to recurrent typical or atypical chest pain were eligible to participate in this prospective study. Key inclusion criteria, in addition to chest pain, was the existence of isolated-MB on the left anterior descending artery (LAD) and systolic MB-compression $\geq 50 \%$ diameter stenosis (DS), after intracoronary administration of $200 \mu \mathrm{g}$ of nitroglycerin (NTG), as measured by quantitative coronary angiography (QCA). Exclusion criteria were: (1) patients aged $\leq 18$ years old; (2) presence of coronary artery disease in the LAD and/or other coronary arteries; (3) acute coronary syndrome with or without ST elevation; (4) any previous myocardial infarction; (5) any previous percutaneous or surgical myocardial revascularization; (6) left ventricular ejection fraction (LVEF) <40\%; (7) left ventricular (LV) hypertrophy; (8) hypertrophic, dilated, or restrictive cardiomyopathies; (9) any valvular heart disease; (10) uncontrolled arterial hypertension; (11) atrial fibrillation (paroxysmal, persistent, or permanent); and (12) renal failure (acute or chronic).

\subsection{Study Protocol}

Each patient underwent standard two-dimensional echocardiography, treadmill-exercise stress echocardiography (SE), computed-tomography coronary angiography (CTCA), invasive coronary angiography, and TTDE-CFVR measurements during dobutamine provocation which was performed within 1 month after the invasive procedure. Study patients without objective signs of myocardial ischemia on exercise-SE were referred to CTCA in order to rule-out the presence of coronary lesion/s (fixed coronary stenosis, coronary ectasia, or $\mathrm{MB}$ ) as a possible cause of chest pain. If CTCA showed the presence of intramyocardial LAD segment penetrating the interventricular septum at a depth of at least $1.0 \mathrm{~mm}$ from the anterior interventricular groove surface (deep type of $\mathrm{MB}$ ) and no fixed stenosis on any epicardial coronary artery, then invasive coronary angiography was performed. Antianginal drugs (beta-blockers, calcium-channel blockers, long-acting nitrates, trimetazidine, and ranolazine) and xanthine-containing foods or beverages (coffee, tea, sugar drinks, sweets, chocolate, and fruits), were discontinued 24 to 48 h before exercise-SE, invasive 
coronary angiography and TTDE-CFVR measurements, separately. The study protocol was approved by the Ethical Committees of University Clinical Center of Serbia and Faculty of Medicine University of Belgrade (Belgrade, Serbia). Informed consent was obtained from all patients.

\subsection{Exercise Stress-Echocardiography}

Following a standard two-dimensional echocardiography examination, all patients underwent treadmill exercise-SE according to the maximal Bruce protocol, as previously described $[13,27,28]$. Briefly, a senior echocardiographer blinded to patients' clinical, angiographic, and functional status analyzed and interpreted echocardiographic images using a cardiovascular ultrasound system (Acuson Sequoia C256, Siemens Medical Solutions USA, Mountain View, CA, USA) with a 3V2C multifrequency transducer using second-harmonic technology. Based on the 17-segment model, the segmental walls motion in the LV was categorized as follows: 1 = normal, 2 = hypokinetic, $3=$ akinetic, and $4=$ dyskinetic [29]. Myocardial ischemia was deemed to exist when new wall-motion abnormalities (WMA) appeared in at least two adjacent LV segments in the LAD territory during the exercise-SE test.

\subsection{Quantitative Coronary Angiography}

Invasive coronary angiography and detailed frame-by-frame QCA analysis of the interpolated reference diameter, minimal luminal diameter (MLD), and percent DS, at the most severe MB-site, were performed as previously described in detail elsewhere [14,30]. Briefly, all angiographic images were obtained at least 1 min after ic. administration of $200 \mu \mathrm{g}$ of NTG and analyzed in the same views and with the same positioning of the cursor at both end-systole (peak of T wave) and end-diastole (beginning of QRS complex). A senior investigator blinded to the patients' clinical, functional, and echocardiographic status analyzed the images offline using a QCA system (Siemens Quantcor QCA, Siemens Healthineers AG, Erlangen, Germany).

\subsection{Coronary Flow Velocity Reserve Measurements by Transthoracic Doppler Echocardiography}

The same ultrasound unit was used to assess CFVR during dobutamine provocation, as had been described in detail previously [13]. To adequately measure CFVR at peak dobutamine dose, the goal was to achieve an increase in heart rate (HR) $\geq 50 \mathrm{bpm}$ from baseline and/or a HR $\geq 75 \%$ of the maximum predicted for age [31]. Before and during testing, systemic hemodynamic parameters (HR and blood pressure) and 12-lead ECG were continuously monitored. The rate-pressure product (RPP) was computed as $\mathrm{HR} \times$ systolic-BP $(\mathrm{bpm} \times \mathrm{mmHg})$. At the end of the procedure, metoprolol iv. $(2.5-5.0 \mathrm{mg}$ over 1-2 min) were administrated until the normalization of HR (50-80 bpm).

Maximal (peak) diastolic coronary flow velocities (CFVs) under basal conditions and during maximal hyperemia induced by peak dobutamine infusion (30 or $40 \mu \mathrm{g} / \mathrm{kg} / \mathrm{min}$ ) were measured in the distal segment of LAD, by a senior investigator who was blinded for the patient's clinical and functional status (Figure 1). CFVR was calculated as the ratio between peak diastolic CFV obtained during peak dobutamine infusion and peak diastolic CFV under basal conditions. 

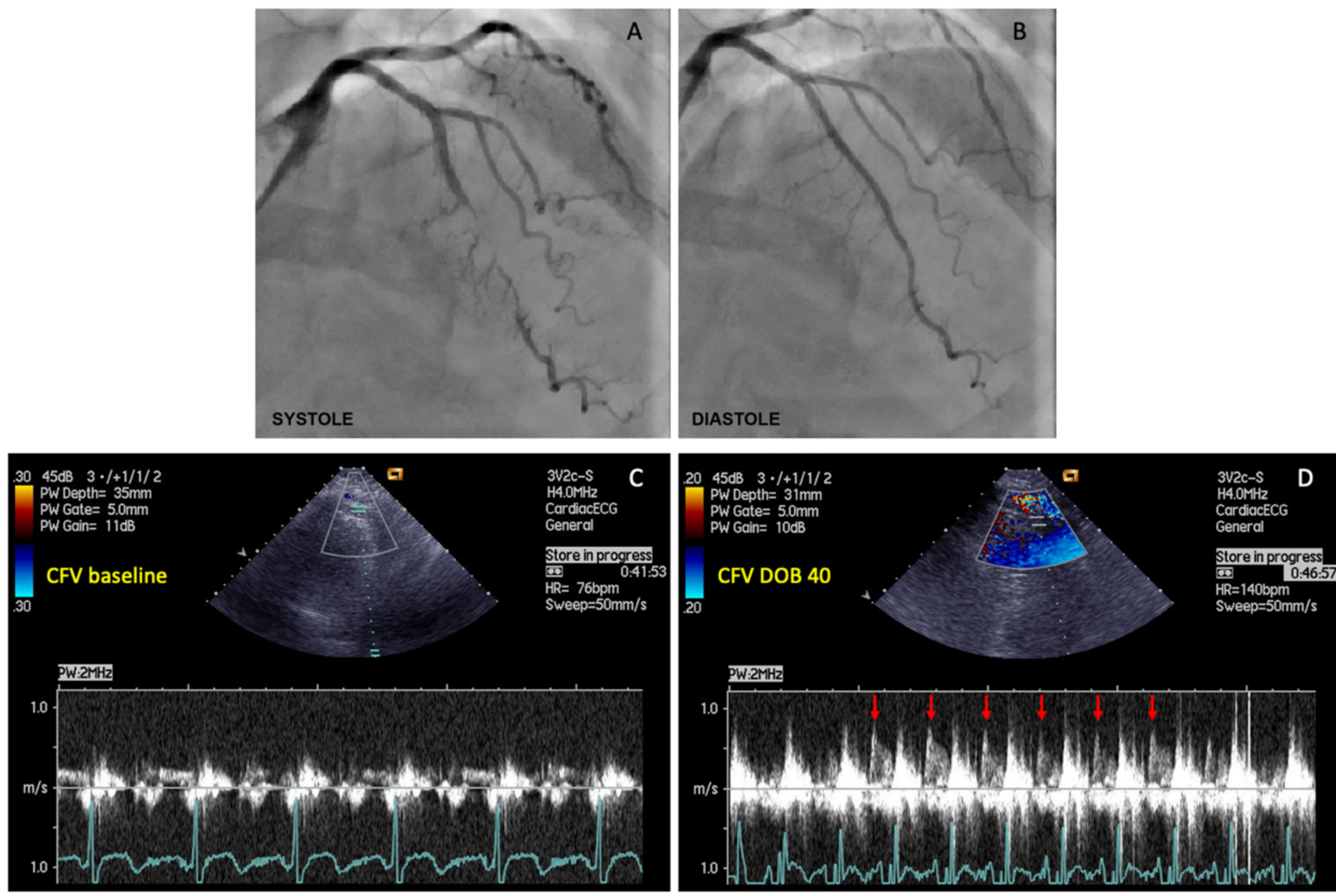

Figure 1. The example of coronary flow velocity reserve (CFVR) measurements obtained by transthoracic Doppler echocardiography (TTDE) in the left anterior descending (LAD) artery distal to the myocardial bridging (MB), before and during iv. infusion of high-dose dobutamine ( $40 \mu \mathrm{g} / \mathrm{kg} / \mathrm{min})$. (A) Coronary angiography revealed myocardial bridging (MB) with severe intramyocardial LAD segment compression (>90\% diameter stenosis) during systole; (B) Coronary angiography showed a significant decompression of intramyocardial LAD segment during diastole in the same patient; (C) CFV measurement under basal conditions (CFV baseline), and (D) CFV measurement at peak dobutamine dose (CFV DOB 40). The heart rate under basal conditions was 76 bpm, while during peak dobutamine infusion was $140 \mathrm{bpm}$ (delta-HR $64 \mathrm{bpm}$ ). Coronary flow velocity reserve equals 2.96 (CFV DOB 40/CFV baseline $=0.77 / 0.26=2.96$ ). Red arrows showing characteristic diastolic CFV profile during peak dobutamine infusion in the LAD distal to the MB. This phenomenon is characterized by an abrupt acceleration followed by rapid deceleration of the CFV at early-diastole and flow plateau during mid-to-late diastole ("finger-tip" phenomenon). CFV = coronary flow velocity; DOB $40=$ dobutamine at $40 \mu \mathrm{g} / \mathrm{kg} / \mathrm{min}$.

\subsection{Statistical Analysis}

Statistical analysis of the data was performed using IBM SPSS Statistics for Windows, version 26.0 (IBM Corporation, Armonk, NY, USA). Categorical variables are presented as counts with percentages and continuous variables as means \pm standard deviations (SD). Kolmogorov-Smirnov and Levene tests were used to verify the normal distribution of continuous variables. Differences between categorical variables were analyzed using a Chi-squared or Fischer's exact test, depending on group size, whereas those between continuous variables were analyzed using a Student's $t$-test (paired or unpaired) as appropriate. A Pearson correlation coefficient, along with a linear regression model, is used to estimate the correlation between continuous variables. ANOVA for repeated measures was used to determine differences in hemodynamic parameters measured under basal conditions and during peak dobutamine infusion. To assess the most appropriate cut-off value of CFVR during peak dobutamine infusion for stratifying MB-patients with and without stress-induced myocardial ischemia, receiver operating characteristic (ROC) curve with 
95\% confidence intervals (CI) and the highest Youden's index (sensitivity + specificity-1) was used. Cohen's kappa coefficient was applied to evaluate the agreement between two dichotomous variables: exercise stress-induced myocardial ischemia $(0=$ absent; $1=$ present $)$, and TTDE-CFVR $(0=$ CFVR greater than cut-off value; $1=$ CFVR less than/equal to cut-off value). Univariate binary logistic regression was used to identify whether different variables are significantly associated with established ischemic CFVR values. To establish variables independently associated with ischemic CFVR values in MB-patients, univariate predictors with a value of $p<0.2$ were included in a multivariate regression model using a backward method. Statistical significance was defined as a two-sided value of $p<0.05$.

\section{Results}

Mean systolic compression of the intramyocardial LAD segment was $62 \pm 10 \%$ (range: $51-95 \%$ DS). At peak dobutamine dose, the HR $\geq 50 \mathrm{bpm}$ from baseline was achieved in all patients $(100 \%)$, whereas the HR $\geq 75 \%$ of maximum age-predicted HR was achieved in 73 patients $(90 \%)$. However, due to the onset of chest pain and/or ischemic ECG changes, the remaining 8 patients (10\%) were not able to reach $\mathrm{HR} \geq 75 \%$ of maximum age-predicted HR during dobutamine provocation, requiring an earlier termination of the test. There were no major complications. Dobutamine provocation caused ventricular bigeminy in one patient, which was resolved after its cessation and concomitantly administering metoprolol (2.5-5.0 mg).

Stress-induced myocardial ischemia with the occurrence of WMA in medial and distal segments of the anterior septum was found in 23 patients (28\%). Thirteen of 23 patients with WMA and 1 of 58 patients without WMA had ST depressions $\geq 1.0 \mathrm{~mm}$ during exercise ( 56.5 vs. $1.7 \%, p<0.001$ ). Exercise-induced chest pain was experienced by 11 of 23 patients with VMA and 11 of 58 patients without VMA (47.8 vs. 19.0\%, $p=0.013$ ).

Tables 1 and 2 summarize demographic, clinical, and angiographic characteristics of MB-patients regarding the presence of stress-induced VMA during exercise-SE. In terms of demographic and clinical variables, no significant differences were found between SE-positive and SE-negative groups. At end-diastole, percent DS was significantly higher, and MLD significantly lower in SE-positive in comparison to SE-negative group ( $39 \pm 8$ vs. $27 \pm 8 \%, p<0.001 ; 1.55 \pm 0.31$ vs. $1.96 \pm 0.36 \mathrm{~mm}, p<0.001$, respectively), but not at end-systole ( $64 \pm 12$ vs. $62 \pm 10 \%, p=0.496 ; 0.89 \pm 0.34$ vs. $1.01 \pm 0.29 \mathrm{~mm}$, $p=0.200$, respectively).

Table 1. Demographic and clinical characteristics of MB-patients regarding the presence of stressinduced wall-motion abnormalities (VMA) in the LAD territory.

\begin{tabular}{ccccc}
\hline Variable & $\begin{array}{c}\text { All } \\
(\boldsymbol{n}=\mathbf{8 1})\end{array}$ & $\begin{array}{c}\text { SE } \\
(\boldsymbol{n}=\mathbf{5 8})\end{array}$ & $\begin{array}{c}\text { SE }+ \\
(\boldsymbol{n}=\mathbf{2 3})\end{array}$ & $p$-Value \\
\hline Age \pm SD, years & $56 \pm 10$ & $55 \pm 10$ & $57 \pm 9$ & 0.275 \\
Gender, males (\%) & $55(68)$ & $38(65)$ & $17(74)$ & 0.466 \\
BMI \pm SD, $\mathrm{kg} / \mathrm{m}^{2}$ & $27.0 \pm 3.9$ & $27.1 \pm 4.1$ & $26.5 \pm 3.5$ & 0.526 \\
Hypertension, $n(\%)$ & $59(73)$ & $45(78)$ & $14(61)$ & 0.127 \\
Diabetes, $n(\%)$ & $10(12)$ & $7(12)$ & $3(13)$ & 0.904 \\
Smoking, $n(\%)$ & $37(46)$ & $26(45)$ & $11(48)$ & 0.807 \\
Hyperlipidemia, $n(\%)$ & $59(73)$ & $44(76)$ & $15(65)$ & 0.331 \\
Family history, $n(\%)$ & $49(60)$ & $33(57)$ & $62 \pm 7$ & 0.293 \\
LVEF \pm SD, $\%$ & $64 \pm 8$ & $64 \pm 8$ & $15(65)$ & 0.161 \\
Typical chest pain, $n(\%)$ & $44(54)$ & $29(50)$ & $8(35)$ & 0.215 \\
Atypical chest pain, $n(\%)$ & $37(46)$ & $29(50)$ & 0.215
\end{tabular}

Data are expressed as mean \pm SD or as number (\%). SE- = group of MB-patients without stress-induced VMA $\mathrm{SE}+=$ group of MB-patients with stress-induced VMA. BMI = body-mass index; LAD = left anterior descending artery; $\mathrm{LVEF}=$ left ventricle ejection fraction; $\mathrm{MB}=$ myocardial bridging. 
Table 2. Angiographic characteristics of MB-patients regarding the presence of stress-induced wallmotion abnormalities (VMA) in the LAD territory.

\begin{tabular}{ccccc}
\hline Variable & $\begin{array}{c}\text { All } \\
(\boldsymbol{n}=\mathbf{8 1 )}\end{array}$ & $\begin{array}{c}\text { SE }- \\
(\boldsymbol{n}=\mathbf{5 8})\end{array}$ & $\begin{array}{c}\text { SE }+ \\
(\boldsymbol{n}=\mathbf{2 3})\end{array}$ & $\boldsymbol{p}$-Value \\
\hline RD (end-systole) $\pm \mathrm{SD}, \mathrm{mm}$ & $2.59 \pm 0.39$ & $2.64 \pm 0.40$ & $2.47 \pm 0.33$ & 0.126 \\
RD (end-diastole) $\pm \mathrm{SD}, \mathrm{mm}$ & $2.65 \pm 0.40^{*}$ & $2.70 \pm 0.40^{*}$ & $2.53 \pm 0.36^{*}$ & 0.140 \\
MLD (end-systole) $\pm \mathrm{SD}, \mathrm{mm}$ & $0.98 \pm 0.31$ & $1.01 \pm 0.29$ & $0.89 \pm 0.34$ & 0.200 \\
MLD (end-diastole) $\pm \mathrm{SD}, \mathrm{mm}$ & $1.84 \pm 0.39 *$ & $1.96 \pm 0.36^{*}$ & $1.55 \pm 0.31^{*}$ & $<0.001$ \\
DS (end-systole) $\pm \mathrm{SD}, \%$ & $62 \pm 11$ & $62 \pm 10$ & $64 \pm 12$ & 0.496 \\
DS (end-diastole) $\pm \mathrm{SD}, \%$ & $31 \pm 10^{*}$ & $27 \pm 8^{*}$ & $39 \pm 8^{*}$ & $<0.001$ \\
\hline
\end{tabular}

Data are expressed as mean \pm SD or as number (\%). SE $-=$ group of MB-patients without stress-induced VMA; $\mathrm{SE}+=$ group of MB-patients with stress-induced VMA. DS = diameter stenosis; LAD = left anterior descending artery; $\mathrm{MB}=$ myocardial bridging; $\mathrm{MLD}=$ minimal luminal diameter; $\mathrm{RD}=$ reference diameter. ${ }^{*} p<0.05$ vs. end-systole.

\subsection{Coronary Physiological Parameters during Dobutamine Provocation: Relation to} Stress-Induced VMA

Table 3 shows systemic and coronary physiological parameters before and after peak dobutamine infusion regarding the presence of stress-induced VMA during exercise-SE in MB-patients. There were no differences in HR, both systolic and diastolic BP, and RPP before and after peak dobutamine infusion between SE-positive and SE-negative groups. However, both CFV and CFVR after peak dobutamine infusion were significantly lower in SE-positive in comparison to SE-negative group (50.78 $\pm 11.05 \mathrm{vs} .72 .62 \pm 20.74 \mathrm{~cm} / \mathrm{s}$, $p<0.001 ; 1.93 \pm 0.16$ vs. $2.78 \pm 0.54 \%, p<0.001$, respectively) (Table 3, Figure 2).

Table 3. Systemic and coronary physiological parameters before and after peak dobutamine infusion regarding the presence of stress-induced wall-motion abnormalities (VMA) in MB-patients.

\begin{tabular}{|c|c|c|c|c|}
\hline & $\begin{array}{c}\text { All } \\
(n=81)\end{array}$ & $\begin{array}{c}\mathrm{SE}- \\
(n=58)\end{array}$ & $\begin{array}{c}\mathrm{SE}+ \\
(n=23)\end{array}$ & $p$-Value \\
\hline HR, bpm (baseline) & $74 \pm 11$ & $75 \pm 10$ & $72 \pm 11$ & 0.240 \\
\hline HR, bpm (DOBmax) & $139 \pm 9 *$ & $140 \pm 8^{*}$ & $136 \pm 12 *$ & 0.093 \\
\hline $\begin{array}{l}\text { Mean systolic BP, mmHg } \\
\text { (baseline) }\end{array}$ & $129 \pm 13$ & $130 \pm 12$ & $126 \pm 13$ & 0.253 \\
\hline $\begin{array}{c}\text { Mean systolic BP, mmHg } \\
\text { (DOBmax) }\end{array}$ & $133 \pm 17$ & $134 \pm 18$ & $129 \pm 14$ & 0.264 \\
\hline $\begin{array}{l}\text { Mean diastolic BP, } \mathrm{mmHg} \\
\text { (baseline) }\end{array}$ & $82 \pm 10$ & $82 \pm 10$ & $82 \pm 10$ & 0.946 \\
\hline $\begin{array}{c}\text { Mean diastolic BP, } \mathrm{mmHg} \\
\text { (DOBmax) }\end{array}$ & $82 \pm 9$ & $83 \pm 9$ & $80 \pm 7$ & 0.141 \\
\hline $\mathrm{RPP}, \times 10^{3} \mathrm{bpm} \cdot \mathrm{mmHg}$ (baseline) & $9.6 \pm 2.0$ & $9.7 \pm 1.8$ & $9.1 \pm 2.2$ & 0.186 \\
\hline $\mathrm{RPP}, \times 10^{3} \mathrm{bpm} \cdot \mathrm{mmHg}(\mathrm{DOBmax})$ & $18.5 \pm 2.6 *$ & $18.8 \pm 2.4 *$ & $17.6 \pm 2.9 *$ & 0.151 \\
\hline $\mathrm{CFV}, \mathrm{cm} / \mathrm{s}$ (baseline) & $26.42 \pm 6.97$ & $26.47 \pm 7.28$ & $26.30 \pm 6.28$ & 0.804 \\
\hline $\mathrm{CFV}, \mathrm{cm} / \mathrm{s}$ (DOBmax) & $67.44 \pm 21.15 *$ & $72.62 \pm 20.74$ * & $50.78 \pm 11.05 *$ & $<0.001$ \\
\hline CFVR & $2.55 \pm 0.61$ & $2.78 \pm 0.54$ & $1.93 \pm 0.16$ & $<0.001$ \\
\hline
\end{tabular}

Data are expressed as mean \pm SD. SE $-=$ group of MB-patients without stress-induced VMA; SE $+=$ group of MB-patients with stress-induced VMA. $\mathrm{BL}=$ basal conditions, before dobutamine infusion; $\mathrm{BP}=$ blood pressure; $\mathrm{CFV}=$ coronary flow velocity; CFVR = coronary flow velocity reserve; DOBmax = peak dobutamine dose; $\mathrm{HR}=$ heart rate; $\mathrm{RPP}=$ rate-pressure product; ${ }^{*} p<0.05$ vs. baseline. 

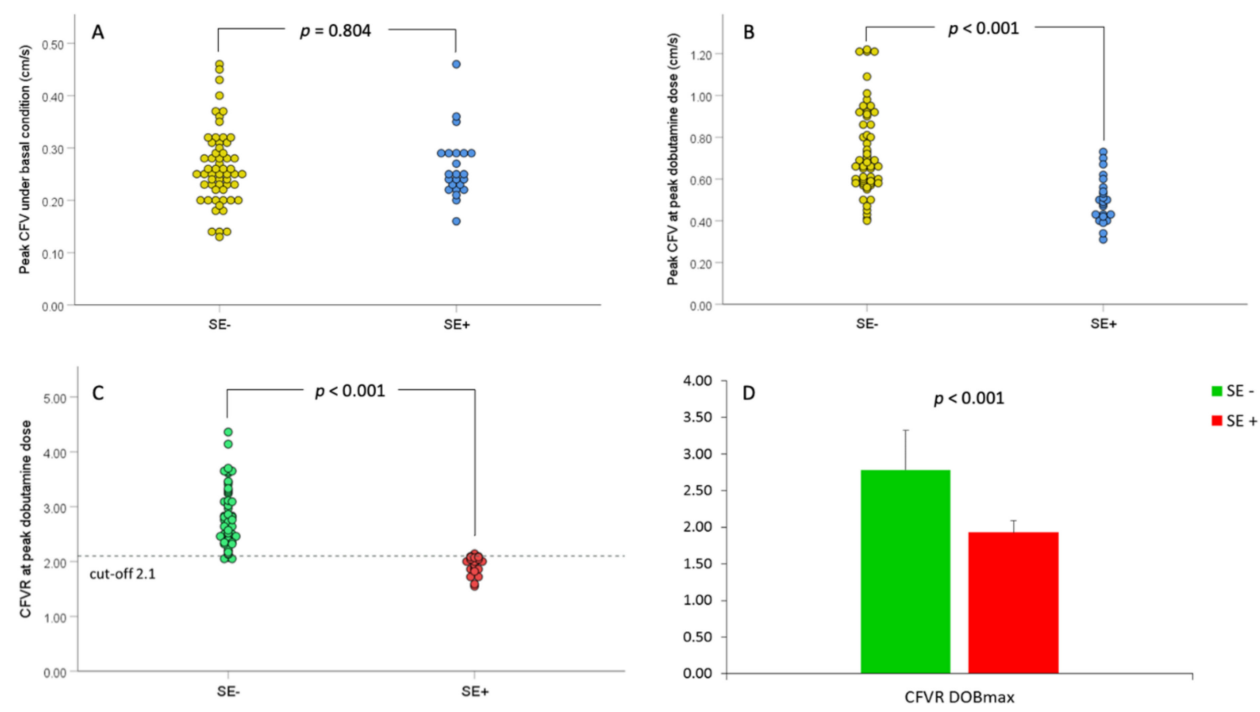

Figure 2. Peak coronary flow velocity (CFV) and coronary flow velocity reserve (CFVR) before and during peak dobutamine dose (DOBmax) in relation to stress-echocardiography (SE) results. (A). Scatterplot of peak CFV values under baseline conditions in relations to SE-results; (B). Scatterplot of peak CFV values during DOBmax in relations to SE-results; (C). Scatterplot of CFVR values in relation to SE-results, and (D). Bar graphs of mean CFVR values before and DOBmax in relation to SE-results. The dashed line in panel $C$ represents the ischemic thresholds for CFVR at peak dobutamine dose (2.1). SE- = group of patients without stress-induced ischemia; $\mathrm{SE}+=$ group of patients with stress-induced ischemia.

\subsection{Diagnostic Value of Coronary Flow Velocity Reserve with Stress-Induced VMA as the Reference Standard}

ROC analyses identified the optimal CFVR cut-off value $\leq 2.1$ obtained during highdose dobutamine ( $>20 \mu \mathrm{g} / \mathrm{kg} / \mathrm{min})$ for the identification of MB associated with stressinduced ischemia, with a sensitivity, specificity, positive and negative predictive value of $96 \%, 95 \%, 88 \%$, and 98\%, respectively (AUC 0.986, 95\% CI: 0.967-1.000, $p<0.001$ ) (Figure 3). The overall diagnostic value of the test was $95 \%$. The classification agreement between dichotomized values of two categorical variables (TTDE-CFVR: $0=>2.1 ; 1=\leq 2.1$; SEresults: $0=$ without stress-induced ischemia, $1=$ with stress-induced ischemia) was high (kappa value $=0.882, p<0.001)$.
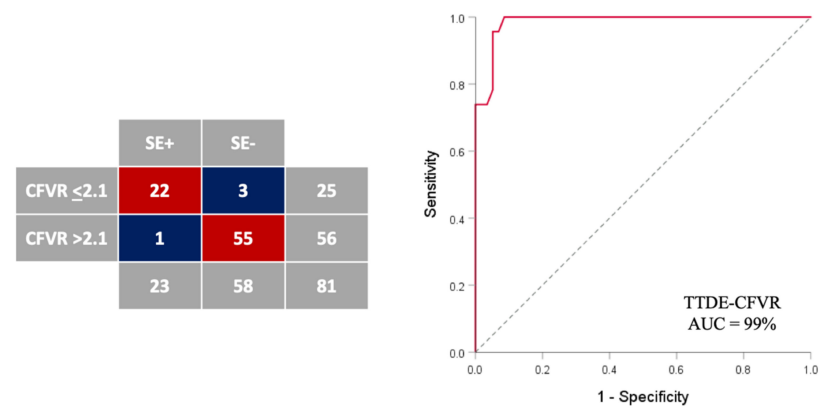

\begin{tabular}{cccccccccc} 
& AUC & SE & p-value & 95\% CI & Cut-off & Sn (\%) & Sp (\%) & PPV & NPV \\
\hline TTDE-CFVR & 0.986 & 0.009 & $<0.001$ & $0.967-1.000$ & 2.1 & $96 \%$ & $95 \%$ & $88 \%$ & $98 \%$ \\
\hline
\end{tabular}

Figure 3. ROC analysis for assessing the accuracy of coronary flow velocity reserve (CFVR) obtained by transthoracic Doppler echocardiography (TTDE) for detection of stress-induced wall-motion abnormalities (VMA) in MB-patients. The overall diagnostic value of the test was $95 \%$ (77/81). $\mathrm{ROC}=$ receiver-operating characteristics curve; $\mathrm{AUC}=$ area under curve; $\mathrm{SE}=$ standard error; $\mathrm{CI}=$ confidence interval; $\mathrm{Sn}=$ sensitivity; $\mathrm{Sp}=$ specificity; $\mathrm{PPV}=$ positive predictive value; $\mathrm{NPV}=$ negative predictive value. $\mathrm{DOBmax}=$ peak dobutamine infusion . 


\subsection{Coronary Physiological Parameters during Dobutamine Provocation: Relation to Angiographic Data}

There were a significant correlations between CFVR and both percent DS at end-systole and end-diastole after peak dobutamine infusion $(\mathrm{r}=0.341, p=0.009 ; \mathrm{r}=-0.295, p=0.024$, respectively), and a borderline correlation between CFVR and MLD at end-systole and end-diastole $(r=-0.229, p=0.083 ; r=0.252, p=0.057$, respectively) (Figure 4). However, multivariate logistic regression analyses showed that MLD and percent DS at MB-site, both at end-diastole, were the only independent predictors of ischemic CFVR values $(\leq 2.1)$ measured after peak dobutamine dose in MB-patients (OR: 0.023, 95\%: 0.001-0.534, $p=0.019 ;$ OR: $1.147,95 \%$ CI: $1.042-1.263 ; p=0.005$, respectively) (Table 4). MLD and percent DS at end-diastole were not analyzed together in the same multivariate analysis due to their high correlation and multicollinearity $(r=-0.667, p<0.001)$.
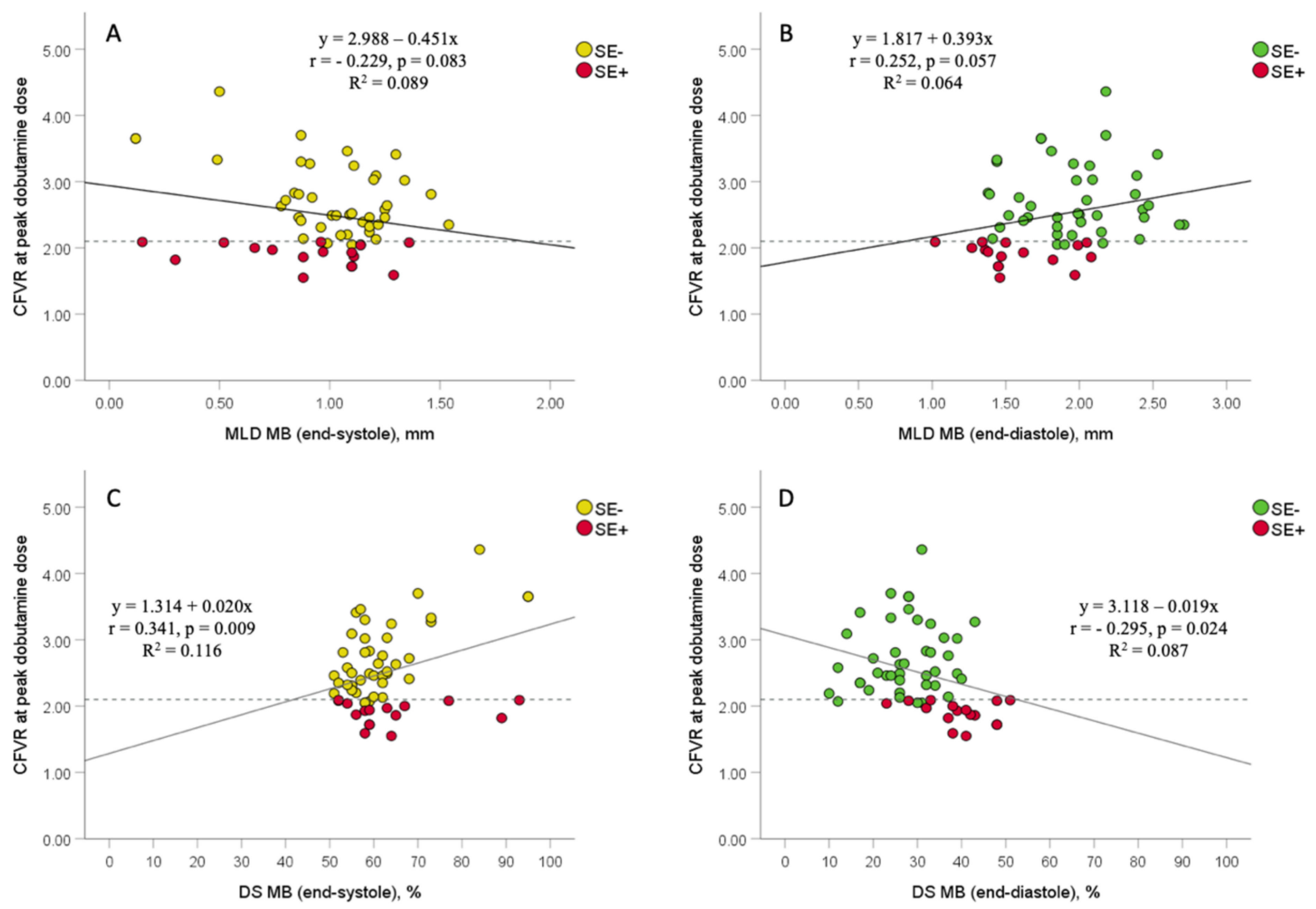

Figure 4. The association between coronary flow velocity reserve (CFVR) obtained by transthoracic Doppler echocardiography (TTDE) and angiographic data (minimal luminal diameter and percent diameter stenosis) in MB-patients, with regards to stress-echocardiography (SE) results. Scatterplots between CFVR and both MLD at end-systole and end-diastole (panels (A,B)), and between CFVR and both percent DS at end-systole and end-diastole (panels (C,D)). Dashed lines represent the ischemic thresholds for CFVR at peak dobutamine dose (2.1), while solid lines represent a linear regression line. $\mathrm{MB}=$ myocardial bridging; $\mathrm{MLD}=$ minimal luminal diameter; $\mathrm{DS}=$ diameter stenosis; $\mathrm{SE}-$ = group of patients without stress-induced ischemia; $\mathrm{SE}+=$ group of patients with stress-induced ischemia. 
Table 4. Multivariate logistic regression analyses for all significant univariate variables $(p \leq 0.2)$ predicting ischemic CFVR value $\leq 2.1$ in MB-patients.

\begin{tabular}{|c|c|c|c|c|}
\hline Univariate Analysis & OR (95\% CI for OR) & $p$-Value & $\mathbf{R}^{2}$ & HL Test $p$-Value \\
\hline Age, years & $1.037(0.982-1.094)$ & 0.182 & 0.033 & 0.411 \\
\hline Gender, males & $1.759(0.604-5.120)$ & 0.300 & 0.019 & 1.000 \\
\hline BMI, $\mathrm{kg} / \mathrm{m}^{2}$ & $0.954(0.841-1.082)$ & 0.461 & 0.010 & 0.975 \\
\hline Hypertension & $0.537(0.193-1.499)$ & 0.235 & 0.024 & 1.000 \\
\hline Diabetes & $1.587(0.406-6.209)$ & 0.507 & 0.007 & 1.000 \\
\hline Smoking & $1.444(0.561-3.722)$ & 0.446 & 0.010 & 1.000 \\
\hline Heredity & $1.239(0.467-3.284)$ & 0.667 & 0.003 & 1.000 \\
\hline Hyperlipidemia & $0.537(0.193-1.499)$ & 0.235 & 0.024 & 1.000 \\
\hline LVEF, \% & $0.950(0.888-1.016)$ & 0.134 & 0.045 & 0.532 \\
\hline Typical chest pain, $\%$ & $1.778(0.674-4.691)$ & 0.245 & 0.024 & 1.000 \\
\hline Atypical chest pain, $\%$ & $0.563(0.213-1.484)$ & 0.245 & 0.024 & 1.000 \\
\hline $\mathrm{RD}$ (end-systole), mm & $0.326(0.073-1.454)$ & 0.142 & 0.054 & 0.666 \\
\hline RD (end-diastole), $\mathrm{mm}$ & $0.340(0.078-1.481)$ & 0.151 & 0.051 & 0.223 \\
\hline MLD MB (end-systole), mm & $0.426(0.074-2.465)$ & 0.341 & 0.022 & 0.080 \\
\hline MLD MB (end-diastole), $\mathrm{mm}$ & $0.072(0.012-0.459)$ & 0.005 & 0.218 & 0.931 \\
\hline DS MB (end-systole), \% & $1.009(0.958-1.062)$ & 0.745 & 0.003 & 0.189 \\
\hline DS MB (end-diastole), \% & $1.145(1.053-1.244)$ & 0.001 & 0.308 & 0.589 \\
\hline $\begin{array}{l}\text { Model 1. Backward Method with Age, LVEF, } \\
\text { RD, and MLD MB at End-Diastole: }\end{array}$ & OR (95\% CI for OR) & $p$-Value & $\mathbf{R}^{2}$ & HL Test $p$-Value \\
\hline Age, years & $1.043(0.970-1.122)$ & 0.252 & 0.314 & 0.224 \\
\hline LVEF, $\%$ & $0.936(0.856-1.024)$ & 0.152 & 0.314 & 0.224 \\
\hline RD (end-diastole), mm & $5.321(0.340-83.172)$ & 0.233 & 0.314 & 0.224 \\
\hline MLD MB (end-diastole), $\mathrm{mm}^{\mathrm{a}}$ & $0.023(0.001-0.534)$ & 0.019 & 0.314 & 0.224 \\
\hline $\begin{array}{l}\text { Model 2. Backward Method with Age, LVEF, } \\
\text { RD, and \%DS MB at End-diastole: }\end{array}$ & OR (95\% CI for OR) & $p$-Value & $\mathbf{R}^{2}$ & HL Test $p$-Value \\
\hline Age, years & $1.059(0.978-1.146)$ & 0.161 & 0.395 & 0.533 \\
\hline $\mathrm{LVEF}, \%$ & $0.939(0.853-1.033)$ & 0.197 & 0.395 & 0.533 \\
\hline RD (end-diastole), mm & $0.438(0.076-2.519)$ & 0.355 & 0.395 & 0.533 \\
\hline DS MB (end-diastole), $\%{ }^{\text {a }}$ & $1.147(1.042-1.263)$ & 0.005 & 0.395 & 0.533 \\
\hline
\end{tabular}

Dependent variable: ischemic CFVR value $\leq 2.1$ in the LAD territory. Multivariate logistic regression analyses were adjusted for all variables with $p \leq 0.2$ in univariate analysis. a only variable in the model $\mathrm{CI}=$ confidence interval; $\mathrm{R}^{2}=$ Nagelkerke $\mathrm{R}$ square, $\mathrm{HL}=$ Hosmer and Lemeshow test. $\mathrm{MB}=$ myocardial bridging; $\mathrm{MLD}=$ minimal luminal diameter; $\mathrm{DS}=$ diameter stenosis; $\mathrm{RD}=$ reference diameter

\section{Discussion}

The present study evaluated for the first time the best cut-off value of CFVR during dobutamine provocation to identify the presence of myocardial ischemia in patients with $\mathrm{MB}$, as compared to the results of exercise-SE test. The major finding of this study is that CFVR during inotropic stimulation with high-doses of dobutamine is feasible, safe, reliable, and clinically useful noninvasive test for physiologic assessment of the MB severity. The optimal cut-off of $\leq 2.1$ for CFVR at peak dobutamine dose, as determined by TTDE, has the best sensitivity, specificity, positive and negative predictive value, for identifying the $\mathrm{MB}$ concerning exercise stress-induced myocardial ischemia. The same cut-off of $\leq 2.1$ for TTDE-CFVR during high-dose dobutamine provocation was suggested in the earlier study by Takeuchi et al. regarding functional evaluation of fixed coronary stenosis [21]. This was the only study, so far, that evaluated CFVR values at peak dobutamine dose obtained by TTDE in the context of dobutamine-induced WMA in the LAD territory. This study showed that CFVR during dobutamine provocation with the ischemic threshold of $\leq 2.1$ had a sensitivity, specificity, positive and negative predictive value of $92 \%, 86 \%, 73 \%$, and $96 \%$, respectively, for detecting the presence of dobutamine-induced myocardial ischemia. Additionally, three other studies which previously compared the value of CFVR during adenosine provocation obtained by TTDE or invasive intracoronary Doppler guidewire, with the results of either dobutamine-SE or single-photon emission computed tomography (SPECT) in patients with fixed LAD stenosis of intermediate severity, demonstrated that CFVR $\leq 2.0$ had similar sensitivity (88-94\%), specificity (89-95\%), positive and negative predictive values (64-94\% and $95-97 \%$, respectively), for detecting ischemia on noninvasive 
tests $[6,21,32]$. Accordingly, our study reinforces previous findings that myocardial ischemia is a unique phenomenon, characterized by different pathophysiological mechanisms in different types of coronary lesions (MB versus fixed stenosis) [14,33]. Similar findings were also presented in studies that compared invasive physiological indices (conventional and diastolic fractional flow reserve, as well as instantaneous wave-free ratio) obtained during both adenosine and dobutamine provocation against the results of noninvasive provocation tests for myocardial ischemia in MB-patients $[10,12,14]$. Therefore, from both clinical and pathophysiological views, dobutamine seems to be the agent of choice for functional evaluation of the MB severity.

The present study showed a high negative predictive value for the CFVR threshold of $2.1(98 \%)$ which is in agreement with previous studies that evaluated the value of CFVR measured either with adenosine or dobutamine provocation for the prediction of myocardial ischemia on noninvasive tests $[6,21,22,32]$. In clinical settings, it means that CFVR $>2.1$ at peak dobutamine dose could safely exclude the presence of functionally significant MB on LAD.

Our study demonstrates that both percent DS and MLD at end-diastole, but not at end-systole, were independent predictors of ischemic CFVR values $\leq 2.1$ during dobutamine provocation, suggesting that coronary blood flow in a coronary artery with $\mathrm{MB}$ mainly depends on the severity of residual MB-compression during diastole. Similarly, our previous study in MB-patients evaluating the role of invasive conventional and diastolic fractional flow reserve measurement during both adenosine and dobutamine provocation has also observed that percent DS at end-diastole and diastolic fractional flow reserve at peak dobutamine dose were the only independent predictors of stress-induced myocardial ischemia [14]. The present study with noninvasive CFVR measured at peak dobutamine dose also supported previous findings by Escaned et al. that MB primarily altered diastolic hemodynamics by generating a significant diastolic pressure gradient across the MB during dobutamine provocation [10,14]. Furthermore, according to studies using QCA and intravascular ultrasound, delayed early diastolic relaxation of the intramyocardial arterial segment is the main hemodynamic disorder of $\mathrm{MB}$ resulting in incomplete MB-decompression at mid-tolate diastole [30,34-38]. Based on these findings, it is reasonable to assume that stress-induced myocardial ischemia in MB-patients is caused by prolonged early diastolic artery relaxation accompanied by persistent reductions in vessel luminal diameter in mid-to-late diastole, which may deteriorate during dobutamine or exercise stress testing due to tachycardia and the consequent shortening of the diastolic perfusion time [30,34-38].

\section{Study Limitations}

Even though exercise-SE is a well-established diagnostic tool in detecting myocardial ischemia, due to its semi-quantitative nature and small areas of WMA, certain patients might be misdiagnosed regarding the presence of myocardial ischemia [28]. However, due to the close relationship between the degree of myocardial ischemia and clinical outcome, and the high sensitivity of exercise-SE, the presence of mild ischemia carries a favorable prognosis [39]. In addition, specifically in these patients suggestive of myocardial ischemia, noninvasive evaluation of CFVR during dobutamine provocation may further classify and risk-stratify MB-patients.

As the most simple and reproducible variable, CFVR, defined as the ratio of hyperemic to basal CFV during diastole, was used in our study since it correlates strongly with coronary perfusion reserve determined by PET [40]. Since the diastolic flow velocities obtained by TTDE depend on the positioning of ultrasound beam, we performed angle correction when necessary.

\section{Conclusions}

Noninvasive CFVR during dobutamine provocation appears to be an additional and important noninvasive tool to determine the functional severity of isolated-MB. A transthoracic CFVR cut-off $\leq 2.1$ measured at a high-dobutamine dose may be adequate for detecting myocardial ischemia in patients with isolated-MB. 
Author Contributions: Conceptualization, S.B.A.; Data curation, S.B.A., A.D.D.-D., V.L.G., M.B.T., M.D.B., M.R.D., V.V., M.V.T., D.N.O., N.B. and I.J.; Formal analysis, S.B.A., A.D.D.-D., V.L.G., M.V.T., M.D.B., N.B. and I.J.; Funding acquisition, M.C.O. and B.D.B.; Investigation, S.B.A., A.D.D.-D., V.L.G., M.V.T., M.D.B., M.R.D., M.V.T., D.N.O., N.B. and I.J.; Methodology, S.B.A., A.D.D.-D., V.L.G., M.B.T., I.A.S., V.V. and B.D.B.; Project administration, S.B.A., M.C.O. and B.D.B.; Resources, S.B.A. and B.D.B.; Software, S.B.A. and I.A.S.; Supervision, S.B.A., A.D.D.-D., G.S. and B.D.B.; Validation, S.B.A., A.D.D.-D. and B.D.B.; Visualization, S.B.A., A.D.D.-D. and B.D.B.; Writing-original draft, S.B.A., and I.A.S.; Writing-review \& editing, A.D.D.-D., M.A.N., G.S. and B.D.B. All authors have read and agreed to the published version of the manuscript.

Funding: This work was supported by the Ministry of Education, Sciences, and Technological Development of the Republic of Serbia (Grant: III41022).

Institutional Review Board Statement: The study was conducted in accordance with the Declaration of Helsinki, and approved by Ethics Committees of University Clinical Center of Serbia and Faculty of Medicine University of Belgrade (Belgrade, Serbia) (approval code: 1435/9; date of approval: 8 September 2011).

Informed Consent Statement: Informed consent was obtained from all subjects involved in the study.

Data Availability Statement: The data presented in this study are available on request from the corresponding author. The data are not publicly available due to privacy or ethical restrictions.

Conflicts of Interest: The authors have no conflicts of interest to disclose.

$\begin{array}{ll}\text { Abbreviations } \\ \text { CFV } & \text { coronary flow velocity } \\ \text { CFVR } & \text { coronary flow velocity reserve } \\ \text { DOB } & \text { dobutamine } \\ \text { DS } & \text { diameter stenosis } \\ \text { MB } & \text { myocardial bridging } \\ \text { MLD } & \text { minimal luminal diameter } \\ \text { LAD } & \text { left anterior descending coronary artery } \\ \text { SE } & \text { stress-echocardiography } \\ \text { QCA } & \text { quantitative coronary angiography } \\ \text { RD } & \text { reference diameter } \\ \text { WMA } & \text { wall-motion abnormalities }\end{array}$

\section{References}

1. Hozumi, T.; Yoshida, K.; Ogata, Y.; Akasaka, T.; Asami, Y.; Takagi, T.; Morioka, S. Noninvasive assessment of significant left anterior descending coronary artery stenosis by coronary flow velocity reserve with transthoracic color Doppler. Circulation 1998, 97, 1557-1562. [CrossRef] [PubMed]

2. Hozumi, T.; Yoshida, K.; Akasaka, T.; Asami, Y.; Ogata, Y.; Takagi, T.; Kaji, S.; Kawamoto, T.; Ueda, Y.; Morioka, S. Noninvasive assessment of coronary flow velocity and coronary flow velocity reserve in the left anterior descending coronary artery by Doppler echocardiography: Comparison with invasive technique. J. Am. Coll. Cardiol. 1998, 32, 1251-1259. [CrossRef]

3. Caiati, C.; Montaldo, C.; Zedda, N.; Bina, A.; Ilicetol, S. New noninvasive method for coronary flow reserve assessment: Contrast-enhanced transthoracic second-harmonic echo-Doppler. Circulation 1999, 99, 771-778. [CrossRef] [PubMed]

4. Caiati, C.; Zedda, N.; Montaldo, C.; Montisci, R.; Iliceto, S. Contrast-enhanced transthoracic second harmonic echo Doppler with adenosine: A noninvasive, rapid and effective method for coronary flow reserve assessment. J. Am. Coll Cardiol. 1999, 34, 122-130. [CrossRef]

5. Caiati, C.; Montaldo, C.; Zedda, N.; Montisci, R.; Ruscazio, M.; Lai, G.; Cadeddu, M.; Meloni, L.; Iliceto, S. Validation of a new noninvasive method (contrast-enhanced transthoracic second harmonic echo Doppler) for the evaluation of coronary flow reserve: Comparison with intracoronary Doppler flow wire. J. Am. Coll. Cardiol. 1999, 34, 1193-1200. [CrossRef]

6. Daimon, M.; Watanabe, H.; Yamagishi, H.; Muro, T.; Akioka, K.; Hirata, K.; Takeuchi, K.; Yoshikawa, J. Physiologic Assessment of Coronary Artery Stenosis by Coronary Flow Reserve Measurements With Transthoracic Doppler Echocardiography: Comparison With Exercise Thallium-201Single-Photon Emission Computed Tomography. J. Am. Coll. Cardiol. 2001, 37, 1310-1315. [CrossRef]

7. Picano, E. Stress Echocardiography, 6th ed.; Springer: Berlin/Heidelberg, Germany, 2015.

8. $\quad$ Lim, H.E.; Shim, W.J.; Rhee, H.; Kim, S.M.; Hwang, G.S.; Kim, Y.H.; Seo, H.S.; Oh, D.J.; Ro, Y.M. Assessment of coronary flow reserve with transthoracic Doppler echocardiography: Comparison among adenosine, standard-dose dipyridamole, and high-dose dipyridamole. J. Am. Soc. Echocardiogr. 2000, 13, 264-270. [CrossRef] [PubMed] 
9. Hakeem, A.; Cilingiroglu, M.; Leesar, M.A. Hemodynamic and intravascular ultrasound assessment of myocardial bridging: Fractional flow reserve paradox with dobutamine versus adenosine. Catheter. Cardiovasc. Interv. 2010, 75, 229-236. [CrossRef] [PubMed]

10. Escaned, J.; Cortés, J.; Flores, A.; Goicolea, J.; Alfonso, F.; Hernández, R.; Fernández-Ortiz, A.; Sabaté, M.; Bañuelos, C.; Macaya, C. Importance of diastolic fractional flow reserve and dobutamine challenge in physiologic assessment of myocardial bridging. J. Am. Coll. Cardiol. 2003, 42, 226-233. [CrossRef]

11. Uusitalo, V.; Saraste, A.; Pietilä, M.; Kajander, S.; Bax, J.J.; Knuuti, J. The Functional effects of intramural course of coronary arteries and its relation to coronary atherosclerosis. JACC Cardiovasc. Imaging 2015, 8, 697-704. [CrossRef] [PubMed]

12. Tarantini, G.; Barioli, A.; Fovino, L.N.; Fraccaro, C.; Masiero, G.; Iliceto, S.; Napodano, M. Unmasking Myocardial Bridge-Related Ischemia by Intracoronary Functional Evaluation. Circ. Cardiovasc. Interv. 2018, 11, e006247. [CrossRef]

13. Aleksandric, S.; Djordjevic-Dikic, A.; Beleslin, B.; Parapid, B.; Teofilovski-Parapid, G.; Stepanovic, J.; Simic, D.; Nedeljkovic, I.; Petrovic, M.; Dobric, M.; et al. Noninvasive assessment of myocardial bridging by coronary flow velocity reserve with transthoracic Doppler echocardiography: Vasodilator vs. inotropic stimulation. Int. J. Cardiol. 2016, 225, 37-45. [CrossRef]

14. Aleksandric, S.B.; Djordjevic-Dikic, A.D.; Dobric, M.R.; Giga, V.L.; Soldatovic, I.A.; Vukcevic, V.; Tomasevic, M.V.; Stojkovic, S.M.; Orlic, D.N.; Saponjski, J.D.; et al. Functional Assessment of Myocardial Bridging With Conventional and Diastolic Fractional Flow Reserve: Vasodilator Versus Inotropic Provocation. J. Am. Heart Assoc. 2021, 10, e020597. [CrossRef]

15. Tarantini, G.; Migliore, F.; Cademartiri, F.; Fraccaro, C.; Iliceto, S. Left anterior descending artery myocardial bridging: A clinical approach. J. Am. Coll. Cardiol. 2016, 68, 2887-2899. [CrossRef]

16. Corban, M.T.; Hung, O.Y.; Eshtehardi, P.; Rasoul-Arzrumly, E.; McDaniel, M.; Mekonnen, G.; Timmins, L.H.; Lutz, J.; Guyton, R.A.; Samady, H. Myocardial bridging: Contemporary understanding of pathophysiology with implications for diagnostic and therapeutic strategies. J. Am. Coll. Cardiol. 2014, 63, 2346-2355. [CrossRef]

17. Alegria, J.R.; Herrmann, J.; Holmes, D.R., Jr.; Lerman, A.; Rihal, C.S. Myocardial bridging. Eur. Heart J. 2005, 26, 1159-1168. [CrossRef]

18. Bourassa, M.G.; Butnaru, A.; Lesperance, J.; Tardif, J.C. Symptomatic myocardial bridges: Overview of ischemic mechanisms and current diagnostic and treatment strategies. J. Am. Coll. Cardiol. 2003, 41, 351-359. [CrossRef]

19. Stoddard, F.M.; Prince, R.C.; Morris, T. Coronary flow reserve assessment by dobutamine transesophageal Doppler echocardiography. J. Am. Coll. Cardiol. 1995, 25, 325-332. [CrossRef]

20. Ahmari, S.A.; Modesto, K.; Bunch, J.; Stussy, V.; Dichak, A.; Seward, J.; Pellikka, P.; Chandrasekaran, K. Doppler derived coronary flow reserve during dobutamine stress echocardiography further improves detection of myocardial ischemia. Eur. J. Echocardiography. 2006, 7, 134-140. [CrossRef]

21. Takeuchi, M.; Miyazaki, C.; Yoshitani, H.; Otani, S.; Sakamoto, K.; Yoshikawa, J. Assessment of coronary flow velocity with transthoracic Doppler echocardiography during dobutamine stress echocardiography. J. Am. Coll. Cardiol. 2001, 38, 117-123. [CrossRef]

22. Meimoun, P.; Benali, T.; Sayah, S.; Luycx-Bore, A.; Boulanger, J.; Zemir, H.; Tribouilloy, C. Evaluation of left anterior descending coronary artery stenosis of intermediate severity using transthoracic coronary flow reserve and dobutamine stress echocardiography. J. Am. Soc. Echocardiogr. 2005, 18, 1233-1240. [CrossRef] [PubMed]

23. Meimoun, P.; Sayah, S.; Tcheuffa, J.C.; Benali, T.; Luycx-Bore, A.; Levy, F.; Tribouilloy, C. Transthoracic coronary flow velocity reserve assessment: Comparison between adenosine and dobutamine. J. Am. Soc. Echocardiogr. 2006, 19, 1220-1228. [CrossRef]

24. Bartunek, J.; Wijns, W.; Heyndrickx, G.R.; de Bruyne, B. Effects of dobutamine on coronary stenosis physiology and morphology: Comparison with intracoronary adenosine. Circulation 1999, 100, 243-249. [CrossRef]

25. Skopicki, H.A.; Abraham, S.A.; Picard, M.H.; Alpert, N.M.; Fischman, A.J.; Gewirtz, H. Effects of dobutamine at maximally tolerated dose on myocardial blood flow in humans with ischemic heart disease. Circulation 1997, 96, 3346-3352. [CrossRef]

26. Severi, S.; Underwood, R.; Mohiaddin, R.H.; Boyd, H.; Paterni, M.; Camici, P.G. Dobutamine stress: Effects on regional myocardial blood flow and wall motion. J. Am. Coll. Cardiol. 1995, 26, 1187-1195. [CrossRef]

27. Beleslin, B.D.; Ostojic, M.; Stepanovic, J.; Djordjevic-Dikic, A.; Stojkovic, S.; Nedeljkovic, M.; Stankovic, G.; Petrasinovic, Z.; Gojkovic, L.; Vasiljevic-Pokrajcic, Z. Stress-echocardiography in the detection of myocardial ischemia. Head-to-head comparison of exercise, dobutamine, and dipyridamole tests. Circulation 1994, 90, 1168-1176. [CrossRef] [PubMed]

28. Pellikka, P.A.; Arruda-Olson, A.; Chaudhry, F.A.; Chen, M.H.; Marshall, J.E.; Porter, T.R.; Sawada, S.G. Guidelines for Performance, Interpretation, and Application of Stress Echocardiography in Ischemic Heart Disease: From the American Society of Echocardiography. J. Am. Soc. Echocardiogr. 2020, 33, 1-41.e8. [CrossRef]

29. Lang, R.M.; Badano, L.P.; Mor-Avi, V.; Afilalo, J.; Armstrong, A.; Ernande, L.; Flachskampf, F.A.; Foster, E.; Goldstein, S.A.; Kuznetsova, T.; et al. Recommendations for cardiac chamber quantification by echocardiography in adults: An update from the American Society of Echocardiography and the European Association of Cardiovascular Imaging. J. Am. Soc. Echocardiogr. 2015, 28, 1-39. [CrossRef]

30. Schwarz, E.R.; Klues, H.G.; vom Dahl, J.; Klein, I.; Krebs, W.; Hanrath, P. Functional, angiographic and intracoronary Doppler flow characteristics in symptomatic patients with myocardial bridging: Effect of short-term intravenous beta-blocker medication. J. Am. Coll. Cardiol. 1996, 27, 1637-1645. [CrossRef]

31. Forte, E.H.; Rousse, M.G.; Lowenstein, J.A. Target heart rate to determine the normal value of coronary flow reserve during dobutamine stress echocardiography. Cardiovasc Ultrasound 2011, 9, 10. [CrossRef] [PubMed] 
32. Joye, J.D.; Schulman, D.S.; Lasorda, D.; Farah, T.; Donohue, B.C.; Reichek, N. Intracoronary Doppler guide wire versus stress single-photon emission computed tomographic thallium-201 imaging in assessment of intermediate coronary stenoses. J. Am. Coll. Cardiol. 1994, 24, 940-947. [CrossRef]

33. Abe, M.; Tomiyama, H.; Yoshida, H.; Doba, N. Diastolic fractional flow reserve to assess the functional severity of moderate coronary stenoses. Comparison with fractional flow reserve and coronary flow velocity reserve. Circulation 2000, 102, 2365-2370. [CrossRef]

34. Schwarz, E.R.; Gupta, R.; Haager, P.K.; vom Dahl, J.; Klues, H.G.; Minartz, J.; Uretsky, B.F. Myocardial bridging in absence of coronary artery disease: Proposal of a new classification based on clinical-angiographic data and long-term follow-up. Cardiology 2009, 112, 13-21. [CrossRef]

35. Schwarz, E.R.; Klues, H.G.; vom Dahl, J.; Klein, I.; Krebs, W.; Hanrath, P. Functional characteristics of myocardial bridging: A combined angiographic and intracoronary Doppler flow study. Eur. Heart J. 1997, 18, 434-442. [CrossRef] [PubMed]

36. Klues, H.G.; Schwarz, E.R.; vom Dahl, J.; Reffelmann, T.; Reu Hl Potthast, K.; Schmitz, C.; Minartz, J.; Krebs, W.; Hanrath, P. Disturbed intracoronary hemodynamics in myocardial bridging: Early normalization by intracoronary stent placement. Circulation 1997, 96, 2905-2913. [CrossRef] [PubMed]

37. Ge, J.; Erbel, R.; Rupprecht, H.J.; Koch, L.; Kearney, P.; Görge, G.; Haude, M.; Meyer, J. Comparison of intravascular ultrasound and angiography in the assessment of myocardial bridging. Circulation 1994, 89, 1725-1732. [CrossRef]

38. Ge, J.; Jeremias, A.; Rupp, A.; Abels, M.; Baumgart, D.; Liu, F.; Haude, M.; Goorge, G.; von Birgelen, C.; Sack, S.; et al. New signs characteristic of myocardial bridging demonstrated by intracoronary ultrasound and Doppler. Eur. Heart J. 1999, 20, $1707-1716$. [CrossRef]

39. Sicari, R.; Cortigiani, L. The clinical use of stress echocardiography in ischemic heart disease. Cardiovasc. Ultrasound 2017, 15, 7 [CrossRef] [PubMed]

40. Saraste, M.; Koskenvuo, J.; Knuuti, J.; Toikka, J.; Laine, H.; Niemi, P.; Sakuma, H.; Hartiala, J. Coronary flow reserve measurement with transthoracic Doppler echocardiography is reproducible and comparable with positron emission tomography. Clin. Physiol. 2001, 23, 114-122. [CrossRef] 